\title{
Polyamide-Based Fibers Containing Microwave-Exfoliated Graphite Nanoplatelets
}

\section{GIORGIO NASILLO}

CGA- Centro Grandi Apparecchiature, Università di Palermo, Via Filippo Marini, 14, 90128 Palermo, Italy

\section{ROSSELLA ARRIGO, NADKA TZANKOVA DINTCHEVA, ELISABETTA MORICI}

Dipartimento di Ingegneria Civile, Ambientale, Aerospaziale, dei Materiali, Università di Palermo, Viale delle Scienze, Ed. 6, 90128 Palermo, Italy

\section{DELIA CHILLURA MARTINO}

Dipartimento Scienze e Tecnologie Biologiche, Chimiche e Farmaceutiche, Università di Palermo, Viale delle Scienze, pad. 17, 90128 Palermo, Italy

\section{EUGENIO CAPONETTI}

CGA- Centro Grandi Apparecchiature, Università di Palermo, Via Filippo Marini, 14, 90128 Palermo, Italy

Correspondence to: N.Tz. Dintcheva; e-mail: nadka.dintcheva@unipa.it.

Received: November 20, 2015

Accepted: May 12, 2016

\begin{abstract}
Exfoliated Graphite NanoPlatelets (GNP) have been obtained from Graphite Intercalation Compounds (GIC) subjected to thermal and microwave treatments. Accurate morphological and structural characterization of obtained GNP, performed to compare the degree of exfoliation, show that microwave-treated GNP, exhibit well-exfoliated structure, without any reduction in dimensions compared with the native GIC, differently to the thermal-treated ones. Microwave-treated GNP have been introduced in polyamide (PA) through melt-mixing to obtain nanocomposite that has been subjected to elongational flow, with the aim to improve the nanofiller dispersion and induce GNP orientation along the fiber direction. Upon extensional flow, really, GNP are able to further exfoliate and to align along the flow direction, leading to obtain advanced nanocomposite with excellent mechanical performance. Finally, both GNP loading and stretching lead to a significant variation in crystalline PA phase, detected by thermal and nuclear magnetic resonance analysis in the solid state. (C) 2016 Wiley Periodicals, Inc. Adv Polym Technol 2016, 0, 21722; View this article online at wileyonlinelibrary.com. DOI 10.1002/adv.21722
\end{abstract}

KEY WORDS: Electron energy loss spectroscopy (EELS), Fibers, Nanoparticles, Polyamides, Transmission Electron Microscopy

\section{Introduction}

$\mathrm{n}$ the last decades, the use of carbonaceous nanoparticles

has attracted a great deal of the research interest, since they exhibit considerable potentials in several fields of application. ${ }^{1,2}$ This feature is due to the unique chemical structure of carbon-based nanoparticles that provides them superior thermal, mechanical, and electrical properties. Among the carbonaceous nanofillers, graphene is usually recognized as the most attractive, ${ }^{3,4}$ even if the realization of its several potential applications is still not feasible, because large-scale production of graphene nanolayers remains a challenge. ${ }^{5}$ In recent years, various synthetic approaches have been pursued to prepare graphene nanoparticles, ${ }^{6,7}$ including the reduction in graphite oxide. However, this method involves the use of strong reducing agents or thermal treatment at elevated temperatures in a vacuum/inert atmosphere. ${ }^{8}$ Recently, increasing attention has been focused on the use of exfoliated graphite and exfoliated graphite nanoplatelets (GNP), as these nanoparticles offer the possibility to isolate few-layered graphitic structures with properties highly similar to those of graphene. ${ }^{9,10}$ Most exfoliated graphite nanofillers are derived from graphite intercalation compounds (GIC), which are compounds of graphite with atoms or molecules (such as alkali metals or mineral acids) intercalated between the carbon layers. ${ }^{11}$ The intercalation process, increasing the interlayer spacing of graphite, weakens the interactions between carbon layers and facilitates the exfoliation of the GIC by mechanical or thermal methods. $^{12,13}$ One of the most common approaches pursued to 
obtain exfoliated graphite nanoparticles concerns the application of mechanical forces to solutions of expandable graphite via stirring or ultrasonication. ${ }^{14}$ Large amounts of expanded graphite can also be produced by chemical exfoliation of bulk graphite. ${ }^{15}$ This method is versatile and it allows to produce a variety of graphite and graphite-based materials, since it is usually combined with chemical functionalization. ${ }^{16}$ A novel approach to obtain GNP involves the use of microwave irradiation; indeed, few seconds of irradiation cause a remarkable volume expansion of pristine GIC, because of the violent expulsion of the volatile intercalation compounds and consequent graphite layer separation. ${ }^{17,18}$ The latter is an attractive exfoliation route because it is cost-efficient and environmentally friend, since no solvents are required to obtain exfoliated structures.

An intriguing field of application of carbon-based nanoparticles is their use as nanofillers in advanced polymer-based nanocomposites. ${ }^{19-21}$ However, the performance of carbonaceous nanoparticles containing nanocomposites is strictly related to the degree of nanofiller dispersion. Obviously, the dispersion of the carbonaceous structures at nanometric level is not easy, because of their high interfacial area and incompatibility with the polymeric matrix. The effect of the elongational flow on the extent of dispersion of carbon-based nanofillers in polymer-based nanocomposites has been accurately studied by our research group, ${ }^{22-25}$ and the obtained results suggest that the elongational flow, being able to align the nanofillers along the fiber direction, is effective to alter the morphology of the nanocomposites.

In this work, commercially available GIC have been subjected to microwave treatment, for comparison, and to classical thermal treatment to obtain GNP, whose extent of exfoliation has been evaluated through accurate morphological and structural characterization. The performed analyses show that the microwave treatment can be considered as an eco-friendly, powerful, and cheap method to prepare exfoliated graphite nanofillers, so as to obtain GNP with high exfoliation degree without reduction in the overall dimensions, which remain comparable to those of native GIC. Moreover, GNP subjected to microwave irradiation have been incorporated in polyamide through melt-mixing, aiming to obtain functional nanocomposite, whose morphology and mechanical performance were deeply investigated, also considering the effect of cold drawing. The last is able to further exfoliate and align GNP along the fiber direction, leading to obtain advanced nanocomposite with excellent mechanical performance.

\section{Experimental}

\section{MATERIALS}

Polyamide 6 (PA) commercialized by the Radici Group (Bergamo, Italy) under the trade name of Radilon $S$ (density $51.13 \mathrm{~g} / \mathrm{cm}^{3}$ and intrinsic viscosity $51.5 \mathrm{dL} / \mathrm{g}$ measured at $30^{\circ} \mathrm{C}$ in $80 \mathrm{vol} \%$ formic acid);

Graphite Intercalation Compounds (GIC) commercialized by Asbury Carbons, (USA), code no 1721, moisture $0.92 \%$, sulfur 3.5\%, pH 4.93, and expansion ratio 1:290.

\section{PREPARATION OF GNP}

To obtain exfoliated graphite nanoplatelets (GNP), pristine GIC have been subjected to two different treatments: (i) a common thermal treatment carried out at $1150^{\circ} \mathrm{C}$ in a high temperature oven (Matest, Treviolo, BG, Italy) for $5 \mathrm{~s}$ followed by a sonication in acetone for $15 \mathrm{~min}^{26-28}$; (ii) an innovative microwave treatment based on recent studies ${ }^{29}$ carried out in a microwave oven (Easytronic in Philips spa, Amsterdam, the Netherlands) at $800 \mathrm{~W}$ for $5 \mathrm{~min}$. Besides, to evaluate the effect of microwave treatment on the graphite nanoplatelets' dimensions, the microwave-treated GNP have been subjected to a further microwave treatment.

\section{PREPARATION OF PA/GNP NANOCOMPOSITE FIBERS}

The PA/GNP system has been obtained by a two-step procedure: first PA and GNP have been dissolved in formic acid to obtain a masterbatch and then in a Brabender mixer neat PA was added to masterbatch in order to obtain a nanocomposite with $3 \mathrm{wt} \%$ filler content. The pristine PA has been subjected to the same processing. The as-spun fibers have been produced using a capillary viscometer (Rheoscope 1000; CEAST, Torino, Italy) operating under a constant extrusion speed $(5 \mathrm{~mm} / \mathrm{min})$, with a die of $1 \mathrm{~mm}$ diameter $\left(D_{0}\right)$ at $240^{\circ} \mathrm{C}$. The filaments have been extruded in air at room temperature. The take-up velocity was about $4 \mathrm{~m} / \mathrm{min}$. The final diameter of the as-spun fibers, $D_{f}$, was about $0.3 \mathrm{~mm}$. The asspun fibers have been subjected to cold drawing with the aid of an Instron machine (model 3365) at room temperature and at a crosshead speed of $100 \mathrm{~mm} / \mathrm{min}$. The initial length was in all the cases $30 \mathrm{~mm}$. The amount of drawing is characterized by the draw ratio: $\mathrm{DR}=L_{f} / L_{0}$, where $L_{f}$ is the final and $L_{0}$ the initial length of the fiber.

\section{CHARACTERIZATION}

In order to investigate the morphology of both GIC and GNP and their modification after the treatments, Transmission Electron Microscopy (TEM) measurements have been performed. SAED (Selected Area Electron Diffraction) measurements were carried out to evaluate the effectiveness of the exfoliation process, while through (Energy Electron Loss Spectroscopy) EELS the thickness of both GIC and GNP has been calculated. For Electron Microscopic analysis, GIC and GNP have been dispersed in toluene and sonicated for $10 \mathrm{~min}$; a drop of each suspension has been deposited in $3 \mathrm{~mm}$ copper grid holey carbon coated (Taab, Berks, UK). TEM micrographs, SAED pattern, and EELS spectra have been acquired using a Jeol JEM 2100 microscope operating a $200 \mathrm{KV}$.

PA and PA/GNP nanocomposite fibers at different draw ratio (DR) were cut with an ultramicrotome (Leica EM UC 6, Milano, Italy) into ultrathin slices with thickness of about $100 \mathrm{~nm}$, placed on 300 mesh copper grid lacey carbon coated (Taab) and then observed using a Jeol JEM 2100 microscope operating a $200 \mathrm{KV}$.

Rheological tests have been performed using a rotational rheometer (ARES G2) in parallel plate geometry 


\section{RESEARCH ARTICLE}

(plate diameter $25 \mathrm{~mm}$ ). The complex viscosity $\left(\eta^{*}\right)$, storage $\left(G^{\prime}\right)$, and loss $\left(G^{\prime \prime}\right)$ moduli were measured performing frequency scans from $\omega=10^{-1}$ to $10^{2} \mathrm{rad} / \mathrm{s}$ at $T=240^{\circ} \mathrm{C}$. The strain amplitude was $\gamma=5 \%$, which preliminary strain sweep experiments proved to be low enough to be in the linear viscoelastic regime.
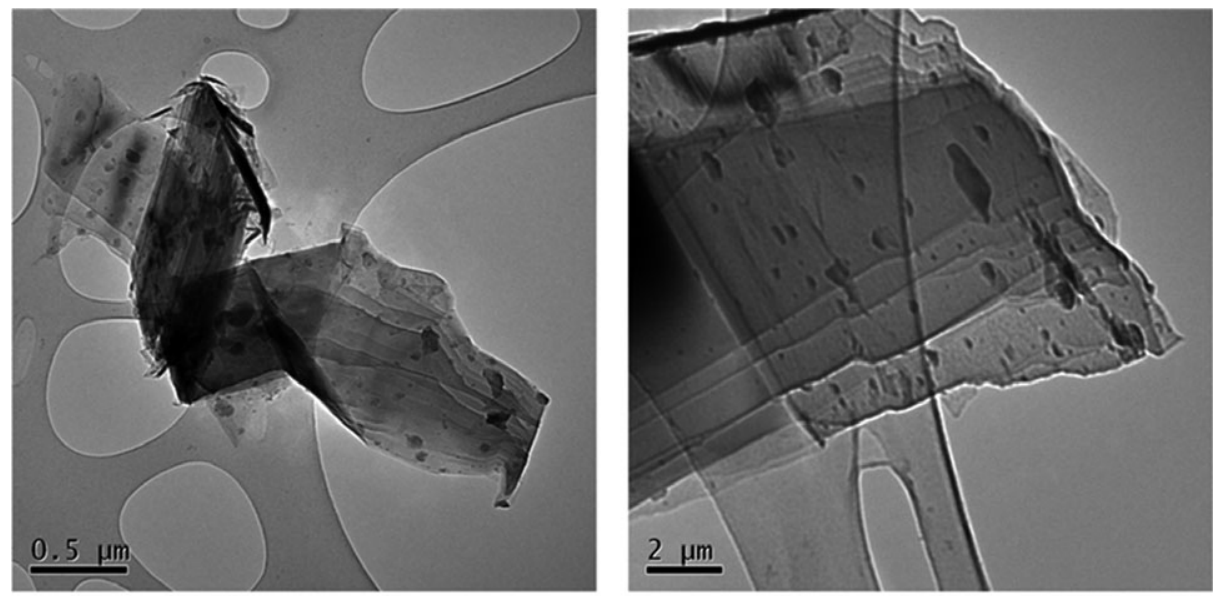

(a)

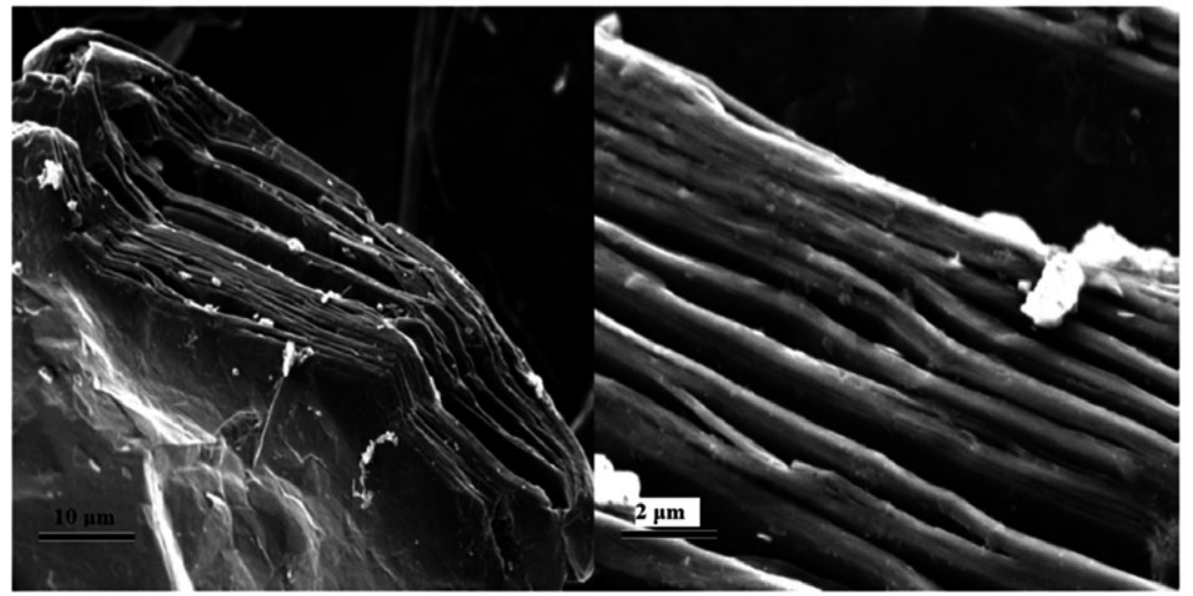

(b)

FIGURE 1. TEM (a) and SEM (b) micrographs at different magnifications of pristine GIC.

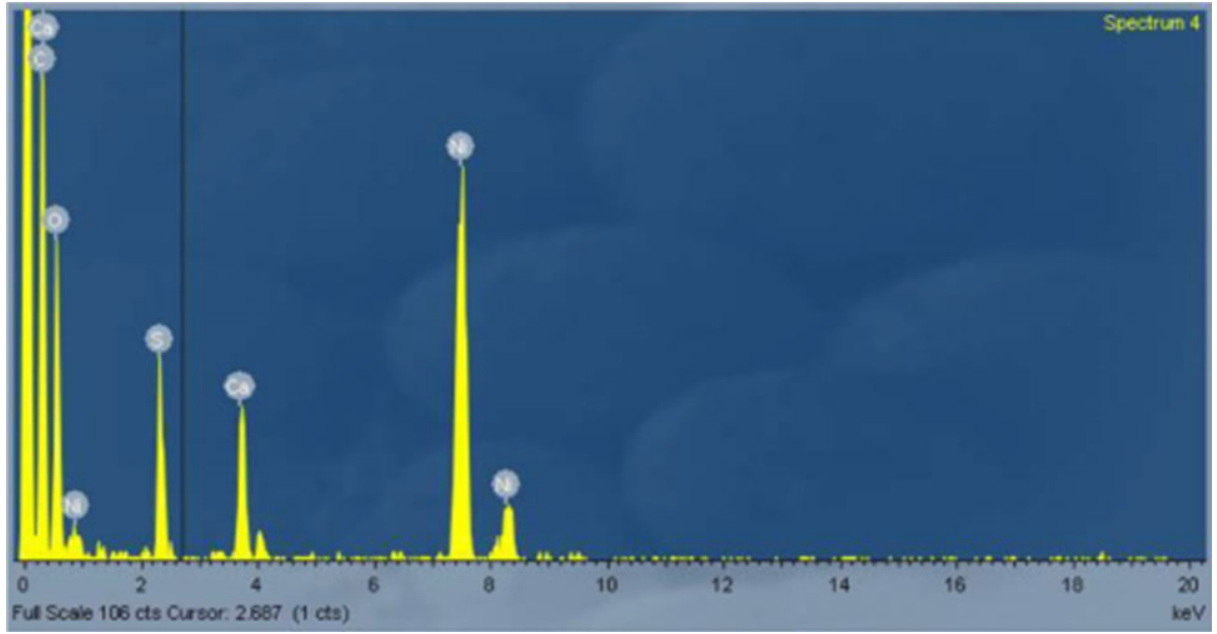

FIGURE 2. EDS spectrum of pristine GIC. 


\section{RESEARCH ARTICLE}

Mechanical tests of the fibers have been carried out using a universal Instron machine (model 3365), according to ASTM D882 (crosshead speed of $100 \mathrm{~mm} / \mathrm{min}$ ). The average values for elastic modulus (E), tensile strength (TS), and elongation at break (EB) were calculated. The standard deviation is reported in the figures.
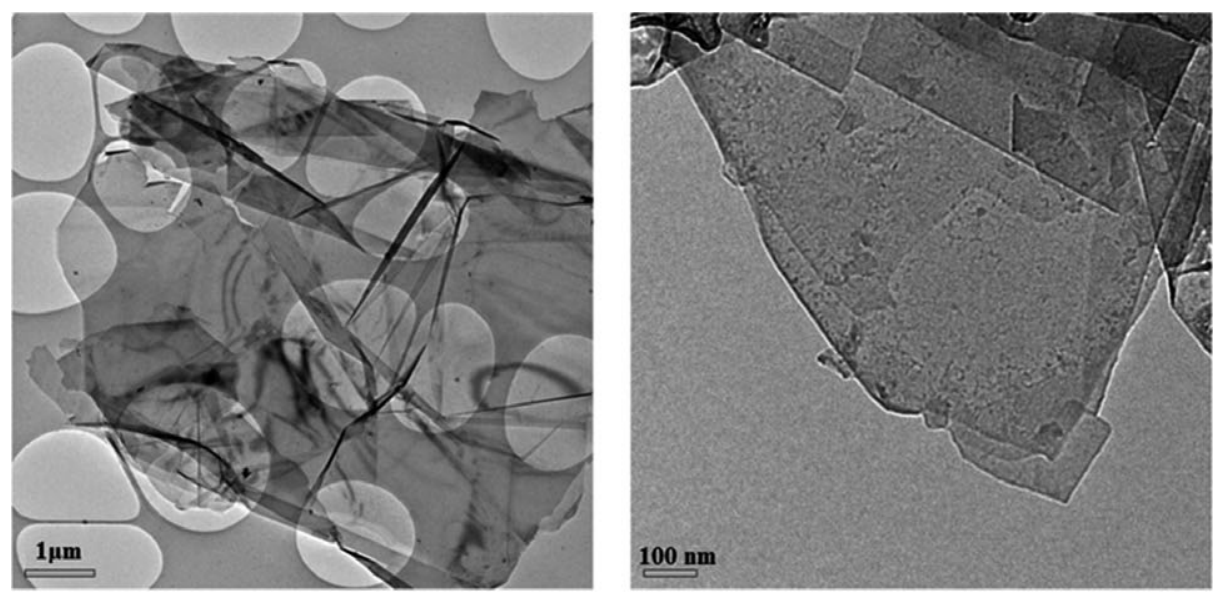

(a)
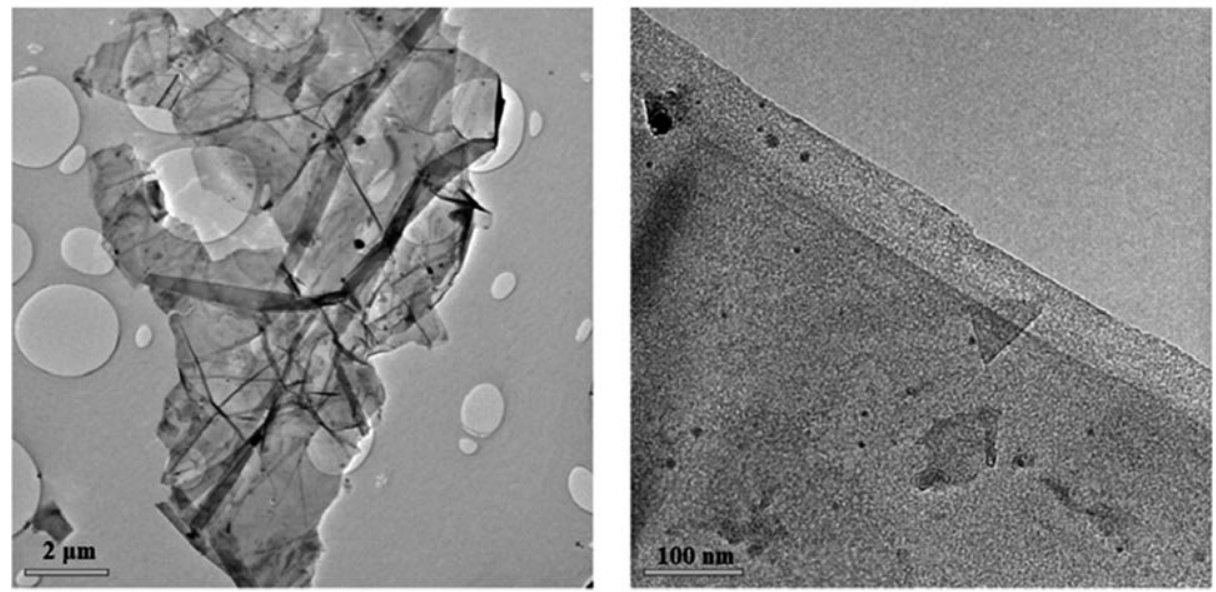

(b)
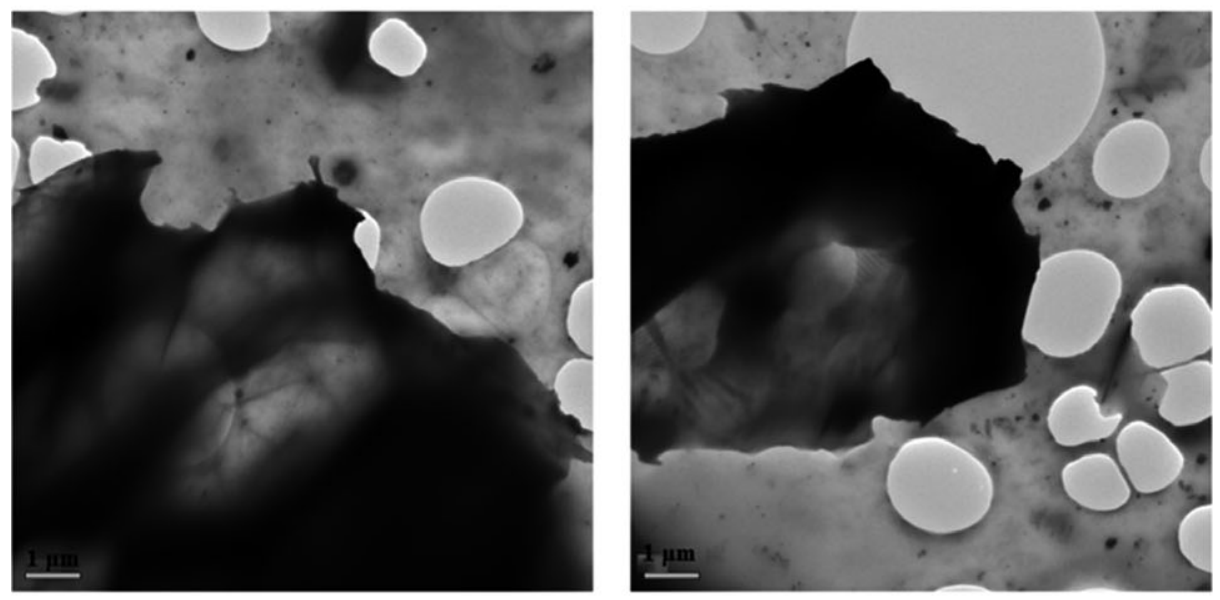

(c)

FIGURE 3. TEM micrographs at different magnifications of GNP after thermal (a) and microwave (b) treatment, as well as, GNP after two subsequent microwave treatments (c). 
Calorimetric data of nanocomposites fibers before and after drawing have been evaluated using differential scanning calorimetry (DSC) on a Perkin-Elmer DSC7, at a scanning rate of $10^{\circ} \mathrm{C} / \mathrm{min}$.

NMR studies have been performed to investigate fillermatrix interactions and molecular-dynamics modification both before and after the process of stretching. The NMR measurements have been performed at room temperature with a spectrometer Bruker Avance II $400 \mathrm{MHz}$ (9.4 T) operating at $100.63 \mathrm{MHz}$ for the ${ }^{13} \mathrm{C}$ with a rotation speed equal to $13 \mathrm{kHz}$ for 1024 scans, a contact time of $1.5 \mathrm{mS}$ and a delay time of $2 \mathrm{~s}$. The optimization of the condition of Hartmann-Hahn ${ }^{30}$ for all samples was obtained using a sample of adamantane. All samples were placed in a $4 \mathrm{~mm}$ zirconia rotors fitted with plugs KEL-F, and filled silica to avoid inconsistency. The values of $\mathrm{T} 1 \rho \mathrm{H}$ and $\mathrm{T} 1 \rho \mathrm{C}$ were obtained with $\tau$ between 0.1 and $7.5 \mathrm{~ms}$ and a contact time of $1.5 \mathrm{~ms}$. The error associated with all values of relaxation times is less than $2 \%$.

\section{Results and Discussion}

\section{CHARACTERIZATION OF PRISTINE GIC AND GNP}

\section{Morphological Observations}

The morphological observations of pristine GIC show a well visible multi-layer structure, see TEM and SEM micrographs reported in Fig. 1(a-b), having an overall thickness of about $15-20 \mu \mathrm{m}$. Besides, EDS spectrum shown in Fig. 2 reveals the presence of oxygen, sulfur, calcium, copper, and nickel atoms in the structure of pristine GIC. The oxygen, sulfur, and calcium are due to the presence of chemical intercalating agent, as calcium sulfate, while copper and nickel come from the sample holder grid. Representative TEM observations at different magnifications of both thermal- and microwave-treated GNP samples are reported in Fig. 3(a-c). The dimensions of GNP after the thermal treatment appear to be significantly reduced with respect to those of pristine GIC,

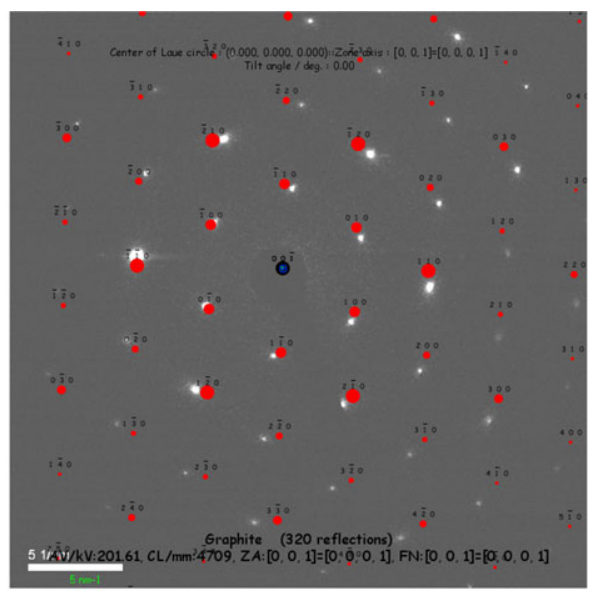

(b)

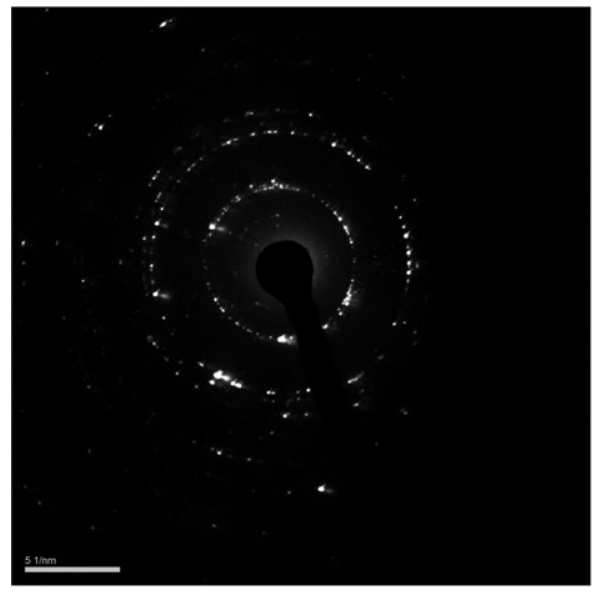

(c)

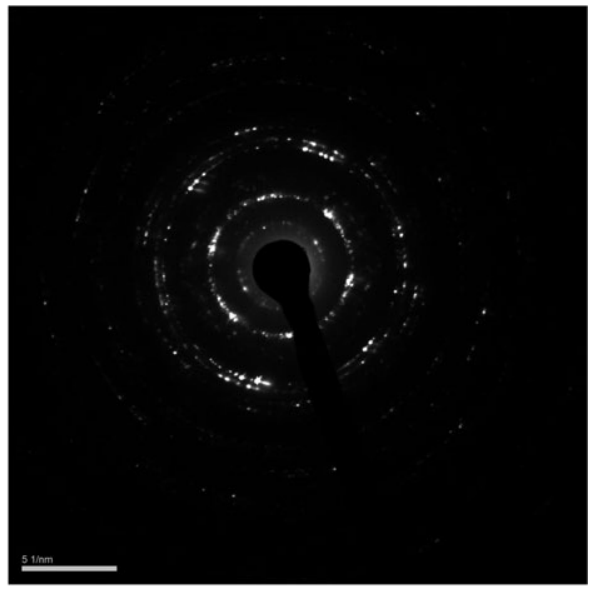

(d)

FIGURE 4. SAED pattern of pristine GIC (a-b) and GNP after thermal (c) and microwave (d) treatment. 


\section{RESEARCH ARTICLE}

reaching about $8-10 \mu \mathrm{m}$. Therefore, the overall dimensions of GIC structures have been reduced at half suggesting that, due to the thermal treatment, a significant reduction in dimensions occurred at high temperature (Fig. 3a). Despite the thermal treatment is detrimental for the nanoparticles' dimensions, some exfoliation of multi-layered structure take place. Differently, the overall dimensions of GNP after microwave treatment remain almost unchanged, i.e., about 15$20 \mu \mathrm{m}$, to the respect of pristine GIC, although the effectiveness of exfoliation is not affected, see Fig. 3 (b). Therefore, the microwave treatment allows to obtain well-exfoliated GNP without reduction in dimensions compared to the native GIC. Further microwave treatment leads to a significant sample damage, as noticeable in Fig. 3(c), and deposition of some amorphous carbon on GNP occurs, probably due to the layers folding and excessive solicitation of the carbon atoms. Further microwave treatment of GNP, hence, cannot be considered useful for the exfoliation of graphite structures.

\section{SAED Analysis}

SAED patterns of pristine GIC displays a regular ordered diffraction spots, which reflects the well-known graphite structure (see Fig. 4(a), left pattern). Moreover, JEMS software ${ }^{31}$ has been used to index the diffraction spot (see red circles in Fig. 4 (b)); the theoretical spots fit perfectly the experimental ones, although they are slightly shifted for a clearer overview. Furthermore, through the performed indexing, it can be concluded that the carbon layers of observed particles are oriented along [ $\left[\begin{array}{lll}0 & 0 & 1\end{array}\right]$ zone axis and that pristine GIC belong to graphite spatial group P $63 \mathrm{~m}$ c. SAED patterns of GNP after thermal and microwave treatments are shown in Fig. 4 (c) and (d), respectively; both patterns display several concentric circles that suggest a loss of ordered layered structures and, consequently, an uneven formation and overlapping of GNP structures. It is worth noting that some electron beam could act as a source for appearance of new diffraction patterns, whose cross main GNP patterns, see Fig. 5. The latter can be
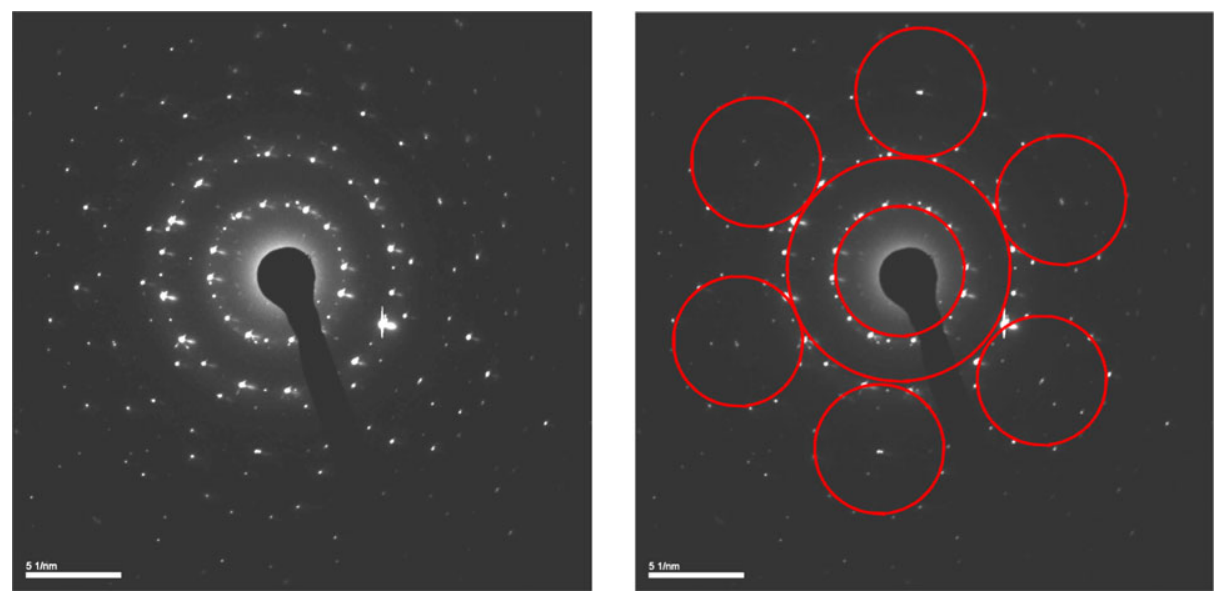

FIGURE 5. SAED patterns of GNP after microwave treatment highlighting the appearance of new diffraction patterns.

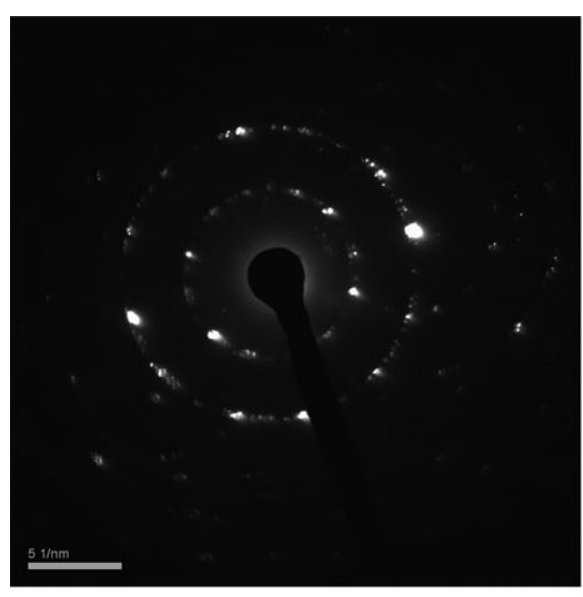

(a)

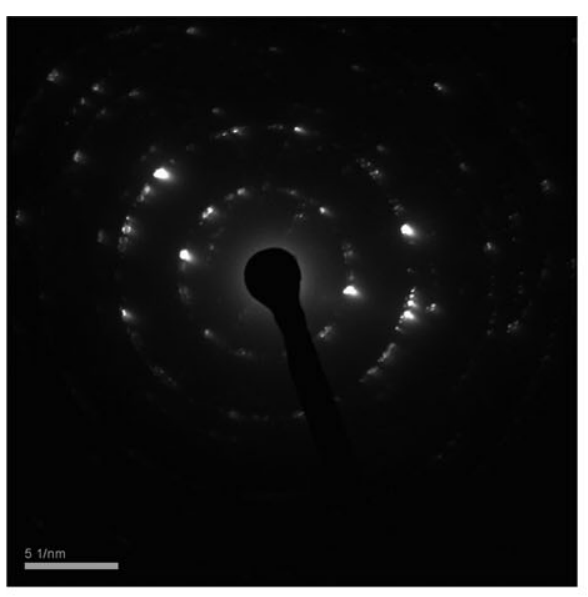

(b)

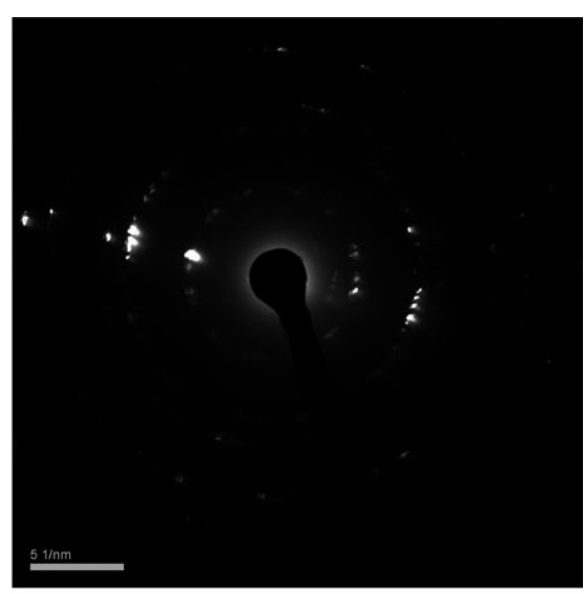

(c)

FIGURE 6. SAED patterns of GNP after microwave treatment (a) and tilted SAED patterns at $4^{\circ}$ (b) and at $8^{\circ}$ (c). 


\section{RESEARCH ARTICLE}

avoided tilting the GNP sample at different angles. For instance, in Fig. 6, the SAED patterns of microwave-treated GNP sample, see (a), and the same pattern tilted at $4^{\circ}$, see (b), and at $8^{\circ}$, see (c), are shown. Tilting the sample, additional diffraction patterns, due to the electron beam source, decrease until they disappear.

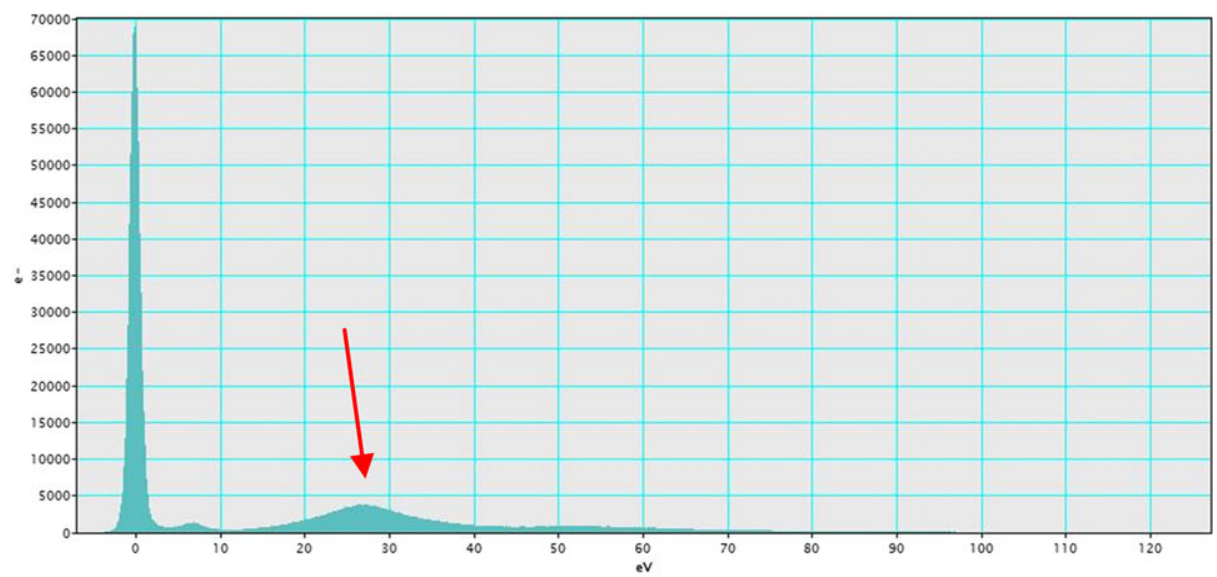

(a)

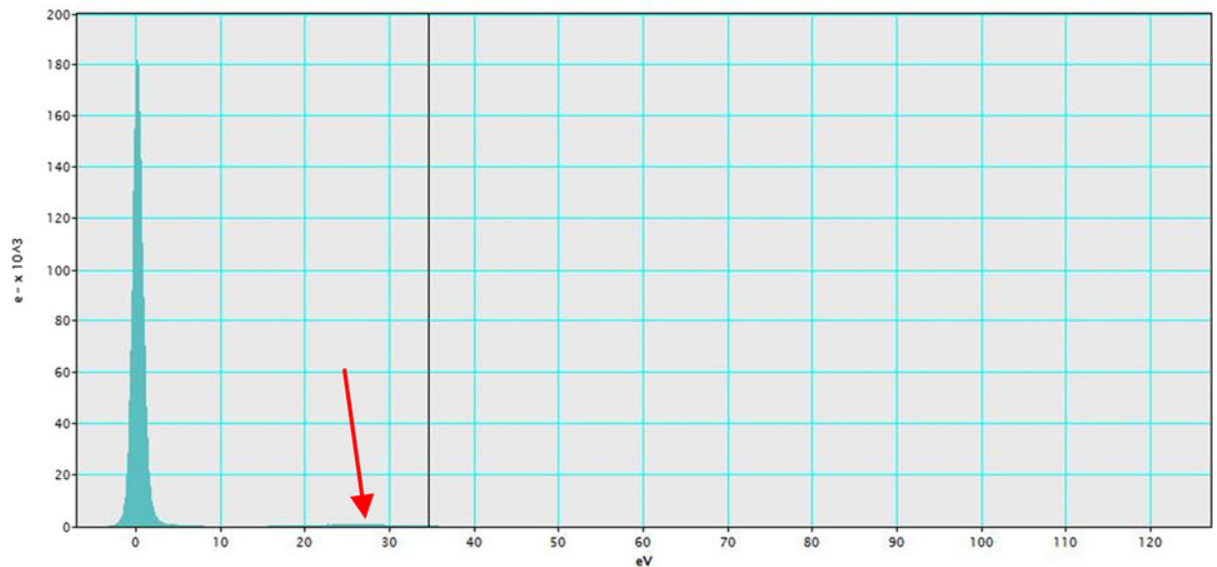

(b)

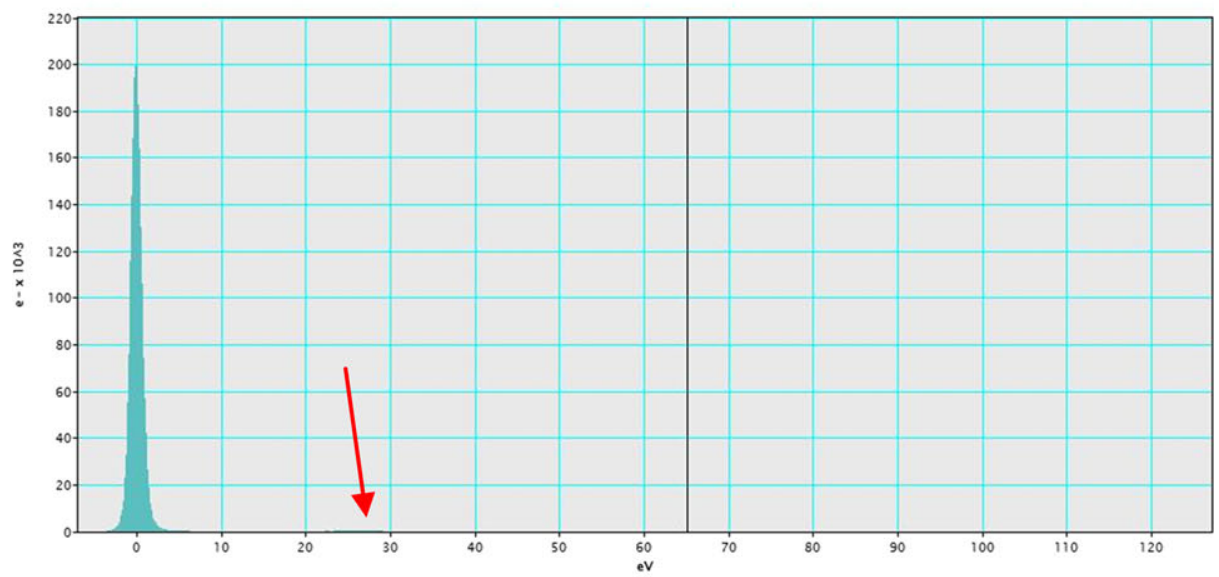

(c)

FIGURE 7. EELS spectra of pristine GIC (a) and GNP after thermal (b) and microwave (c) treatment. 


\section{EELS Spectroscopy}

EELS is an analytical technique that measures the change in kinetic energy of electrons after they have interacted with a sample. In this work, this spectroscopic analysis is considered as a powerful method for the thickness measurement of carbonaceous nanoparticles. Indeed, the total amount of inelastic scattering is directly proportional to the thickness of the sample $(t)$ :

$$
t=\lambda \ln \frac{I_{t}}{I_{0}},
$$

where $I_{0}$ is the intensity of the zero-loss peak (the most intense of the spectrum, at $0 \mathrm{eV}), I_{t}$ is the total intensity of the spectrum in the region of low-loss (including $I_{0}$ ), and $\lambda$ is the mean free path for low-loss energy.

The value of $\lambda$ in the equation above is derived from a parameter calculated by Malis et al. ${ }^{32}$ :

$$
\lambda=\frac{106 F\left(\frac{E_{0}}{E_{m}}\right)}{\ln \left(\frac{2 \beta E_{0}}{E_{m}}\right)}
$$

where $\lambda$ is in $\mathrm{nm}, E_{0}$ in $\mathrm{keV}, \beta$ in mrad, and $F$ is a correction relativistic factor.

$E_{m}$ is the loss of average energy in $\mathrm{eV}$, i.e., for a material of atomic number $Z$, is given by:

$$
E_{m}=7.6 Z^{0.36}
$$

The relativistic factor $F$ is calculated as:

$$
F=\frac{1+\frac{E_{0}}{1022}}{\left(1+\frac{E_{0}}{511}\right)^{2}}
$$

A qualitative analysis of the thickness of both GIC and GNP can be performed considering the intensity of peaks indicated with arrows in the EELS Spectra of Fig. $7(a-c)$. The intensity value decreases significantly for both thermaland microwave-treated GNP, in comparison to that of the native GIC, suggesting a significant thickness in reduction. According to the above calculations, the GIC thickness has been estimated to be about $105-115 \mathrm{~nm}$; considering the distance between the layers in intercalated graphite of about $0.8 \mathrm{~nm}$, each GIC contains, hence, about 130-145 carbon layers. The thickness of GNP subjected to thermal and microwave treatments are about $8-10 \mathrm{~nm}$ and 6-9 $\mathrm{nm}$, respectively, corresponding to 9-12 and 7-11 single layers.

Summarizing, microwave treatment can be considered as an eco-friendly, powerful, and cheap method to prepare exfoliated graphite nanofillers, as it allows to obtain GNP with high exfoliation degree and overall dimensions comparable to those of the native GIC.

\section{CHARACTERIZATION OF PA/GNP NANOCOMPOSITE}

Considering that microwave-treated GNP exhibit well-exfoliated structure, differently to thermal-treated ones, and do not show any reduction in dimensions compared with the native GIC, they have been used for the formulation of PAbased nanocomposites. GNP and PA have been processed through a two-step procedure, involving masterbach preparation and subsequent melt-mixing, and the so formulated nanocomposite has been subjected to elongational flow to improve the nanofiller dispersion and to induce GNP orientation along the fiber direction.

\section{Rheological Characterization}

Rheological measurements have been carried out to characterize the state of dispersion of GNP in host polymeric matrix and to analyze their effect on the rheological behavior of PA. In Fig. 8, the complex viscosity curves of the neat PA and PA/GNP nanocomposite are shown. Neat PA shows a wellpronounced Newtonian behavior in the low frequency region, and a slight $\eta^{*}$ decrease at high frequencies. The $\eta^{*}$ values of PA/GNP nanocomposite are higher than those of neat PA in the whole investigated frequency range, and this effect is particularly pronounced at low frequencies. The disappearance of Newtonian plateau for PA/GNP nanocomposite suggests the formation of a semi-3D network of nanoparticles within PA matrix. The $G^{\prime}$ and $G^{\prime \prime}$ moduli as a function of the frequency

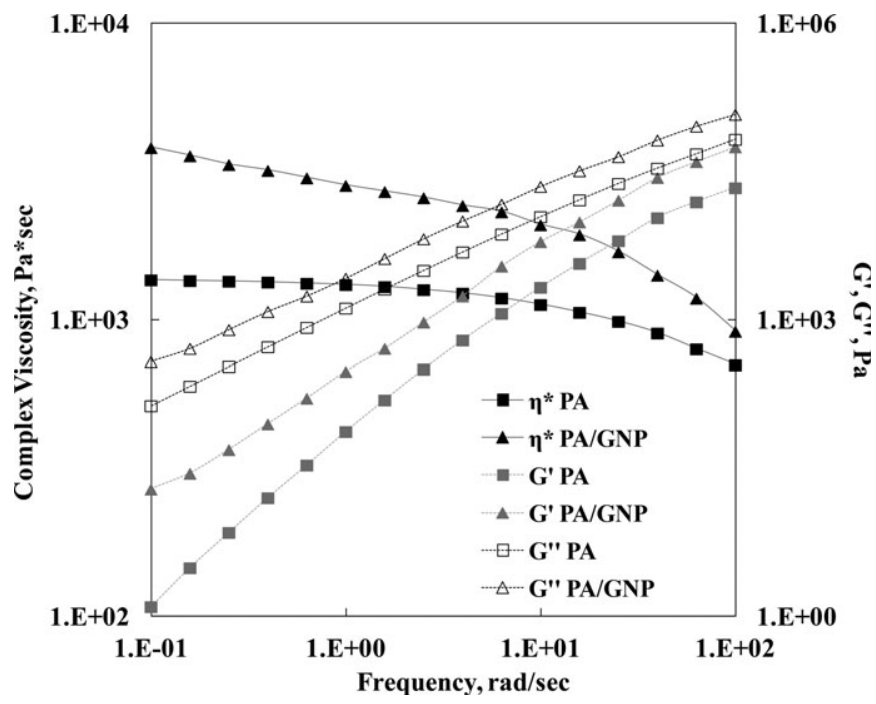

FIGURE 8. Complex viscosity (left axes) and $\mathrm{G}^{\prime}$ and $\mathrm{G}^{\prime \prime}$ moduli (right axes) for neat PA and PA/GNP nanocomposite.

TABLE I Main Mechanical Properties for Neat PA and PA/GNP Nanocomposite at $D R=1$

\begin{tabular}{lccc}
\hline Sample & E, MPa & TS, MPa & EB, \% \\
\hline PA & $1050 \pm 52$ & $110 \pm 5$ & $764 \pm 38$ \\
PA/GNP & $1100 \pm 55$ & $120 \pm 6$ & $550 \pm 25$ \\
\hline
\end{tabular}



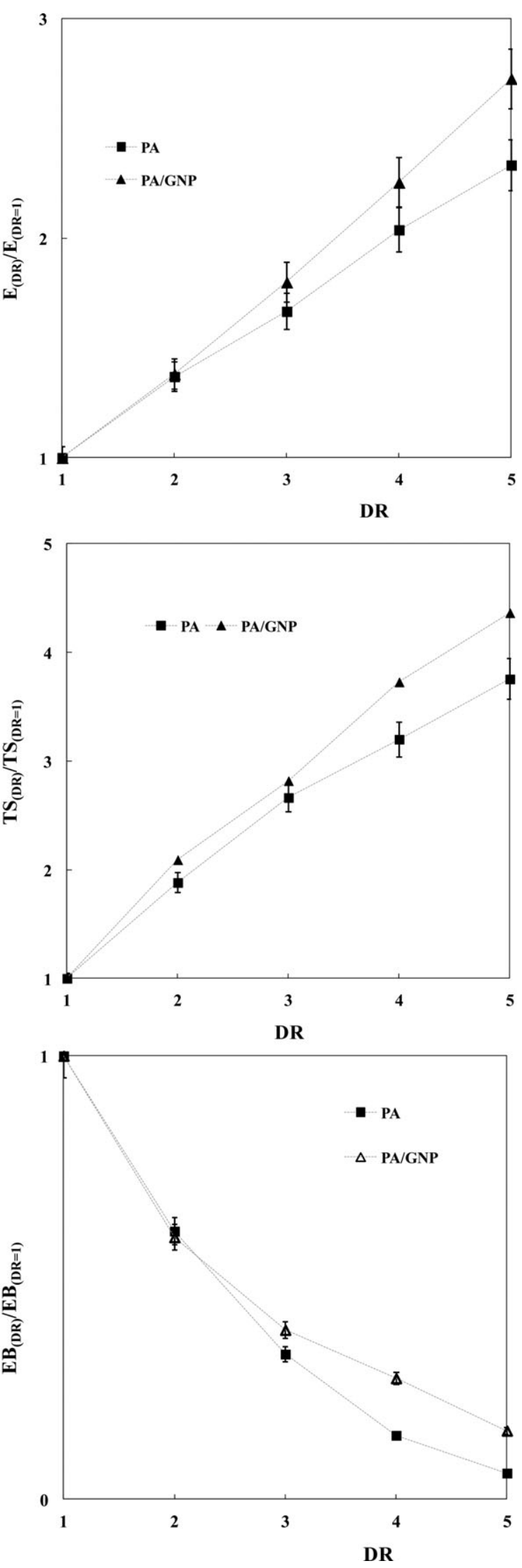

FIGURE 9. Dimensionless Elastic modulus (a), tensile strength (b), and elongational at break (c) as a function of cold drawing for neat PA and PA/GNP nanocomposites fibers.

for neat PA and PA/GNP nanocomposite are also reported in Fig. 8. Both moduli of PA-based nanocomposite increase at all frequencies with the nanoparticles addition, following the same behavior observed for the viscosity. However, the $G^{\prime}$ modulus of PA/GNP nanocomposite tends to become almost independent of the frequency in the low frequency region, indicating a transition from liquid-like to solid-like rheological behavior. In fact, PA/GNP nanocomposite shows non-terminal behavior (i.e., $\left.G^{\prime}(\omega) \propto \omega^{0.8}, G^{\prime \prime}(\omega) \propto \omega^{0.65}\right)$ and this feature occurs when the relaxation of stress tends to an equilibrium value rather than to zero. According to the literature, ${ }^{19}$ this solid-like behavior suggests the occurrence of physical gelation and indicates the existence of a long relaxation time. In the case of carbon nanotubes/polycarbonate nanocomposites, $^{33,34}$ the rheological solid-like behavior is due to the formation of interconnected structure of carbon nanotubes within host matrix. The latter can be also invoked to explain the appearance of a pseudo-plateau in $G^{\prime}$ modulus trend in expandable graphite-containing nanocomposites. ${ }^{35}$ In our case, the non-terminal behavior of PA/GNP nanocomposite clearly indicates the formation of GNP nanoparticles percolated network structure within PA matrix. Moreover, being GNP layered nanoparticles, the observed solid-like rheological behavior can be ascribed to incomplete relaxation of confined PA macromolecules, due to the presence of graphite nanoplatelets.

\section{Mechanical Characterization of Nanocomposite Fibers}

To assess the reinforcement effect of GNP, the mechanical behavior of PA-based nanocomposite fibers has been fully investigated. In Table I, the main mechanical properties, e.g., E, TS, and EB, measured on the as-spun fibers were reported. Upon incorporation of GNP, E and TS of PA slightly increased, while the elongation at break decreased. Therefore, the mechanical test of PA/GNP as-spun fibers overall indicate that the nanocomposite tensile properties are somewhat superior to those of neat PA. To obtain high performance fibers, the as-spun nanocomposite has been subjected to cold drawing with the aim to improve the GNP dispersion and orientation along the fiber direction. Figure 9 shows the trends of dimensionless E, TS, and EB of the PA/GNP nanocomposite fibers, compared with the neat PA, as a function of the draw ratio. The dimensionless values have been obtained by calculating the ratio between the value at specific draw ratio and the corresponding value at $\mathrm{DR}=1$ (as-spun fiber). First, it can be observed that, for both investigated samples, E and TS increase upon increasing the draw ratio; differently, the elongation at break decreases. This feature is likely due to the orientation of PA macromolecules along the fiber direction. Let us consider the nanocomposite mechanical behavior upon elongational flow. GNP addition causes an increase in E and TS, as a function of DR more pronounced with respect to 


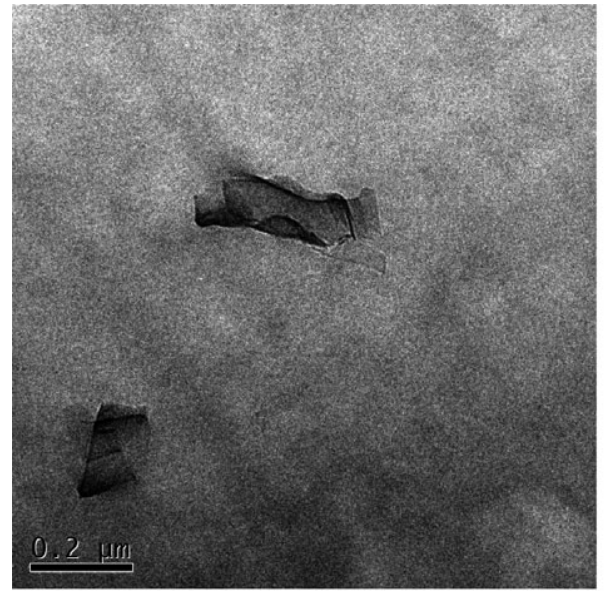

(a)

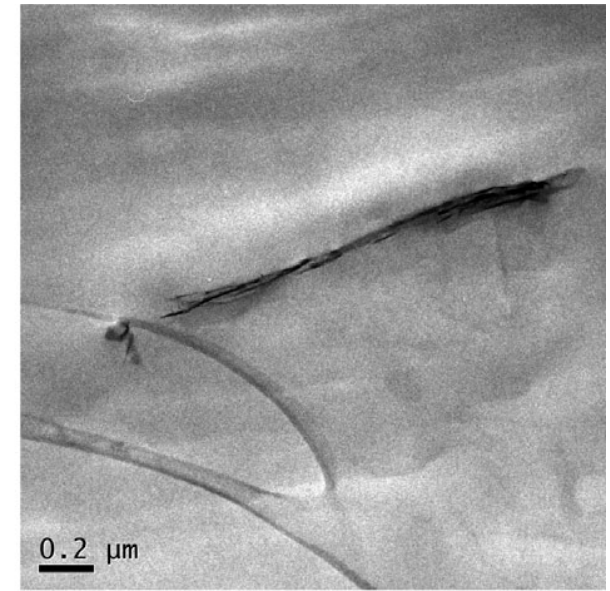

(b)

FIGURE 10. TEM of PA/GNP nanocomposite fibers at $D R=1$ and $D R$ max.

unfilled PA, see Fig. 9 (a-b). This feature cannot be attributed just to the orientation of the PA chains, but the orientation of the nanoparticles along the fiber direction upon elongational flow can be taken into account. The mechanical properties of PA/GNP fibers clearly indicate that extensional flow is able to induce the GNP orientation in the fiber direction upon the drawing, and this issue leads to a dramatic increment of $\mathrm{E}$ and TS as a function of DR. Furthermore, it is worth noting that the distance between the values of $\mathrm{E}$ and TS for unfilled PA and the nanocomposite, increases with increase in the draw ratio. This effect could be ascribed to the improved dispersion of the GNP nanofillers as a function of DR, as well as to the formation of "house of card" structures, similarly to that already observed in polymer/layered clay nanocomposites. ${ }^{36}$ Therefore, due to the lamellar structure of used GNP, an improvement of dispersion and a possible aligning of the nanoparticles along the flow direction upon elongational flow can occur.

\section{Morphological Characterization of Nanocomposite Fibers}

In Fig. 10, TEM micrographs of the radial surface of PA/GNP fibers at minimum and maximum DR were reported. GNP nanoparticles in the PA fibers at DR $=1$ show intrinsic folding tendency, and their orientation is predominantly on the radial fiber direction. After the drawing GNP are aligned along the fiber direction, and as before supposed based on the mechanical results, some sleeping between the carbon layers induced by elongational flow seems occur.

\section{NMR and DSC Measurements of Nanocomposite Fibers}

Figure 11 shows the aliphatic portion of ${ }^{13} \mathrm{C}\{1 \mathrm{H}\}$ CP-MAS NMR spectrum of the neat PA and PA/GNP nanocomposite at minimum and maximum DR with the assignments of the isotropic chemical shift, according to the literature. ${ }^{37}$ In the spectrum of unfilled PA, all signals related to all carbons in

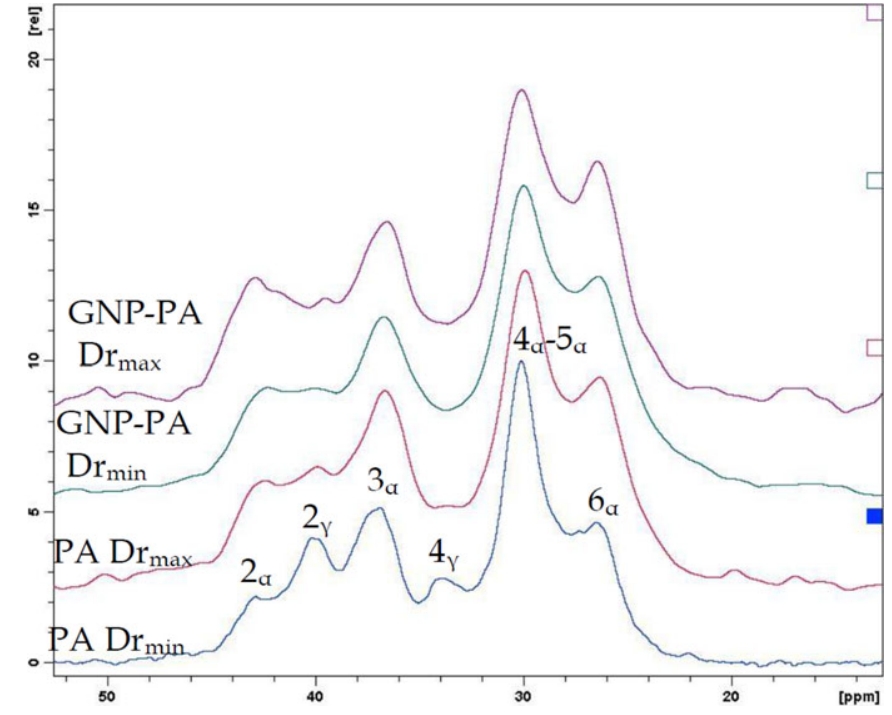

FIGURE 11. $13 \mathrm{C}\{1 \mathrm{H}\}$ CP-MAS NMR spectra of $P A$ and $P A / G N P$ fibers at minimum and maximum draw ratio.

both $\alpha$ and $\gamma$ phases are present. Upon cold drawing, the intensity of the peaks relative to $C \gamma$ decreases, whereas the intensity of the peaks related to $C \alpha$ increases. This issue indicates an orientation of PA macromolecular chains along the stretching direction, since upon elongational flow, the number of hydrogen bonds between the polymer chains increases and the formation of the more stable crystalline form occurs. ${ }^{38}$ In PA/GNP nanocomposite, the variation in the PA crystalline phase from $\gamma$ to $\alpha$ is due to both stretching and presence of nanoparticles.

The effect of stretching and GNP addition on the variation of the crystalline PA phase is also evaluated by DSC analysis, see Fig. 12. The thermogram of the unfilled PA fibers at low DR shows a principal melt peak at $\mathrm{T} \sim 220^{\circ} \mathrm{C}$, attributed to the $\alpha$ crystalline form, and a shoulder at $\mathrm{T} \sim 210^{\circ} \mathrm{C}$, related to the presence of $\gamma$ crystalline phase. The last disappears at 
maximum DR, indicating that, according to NMR analysis, $\gamma$ crystalline form vanishes when PA is subjected to stretching. The DSC heating traces of nanocomposite fibers confirm that the $\gamma$ crystalline form in PA disappears also upon GNP

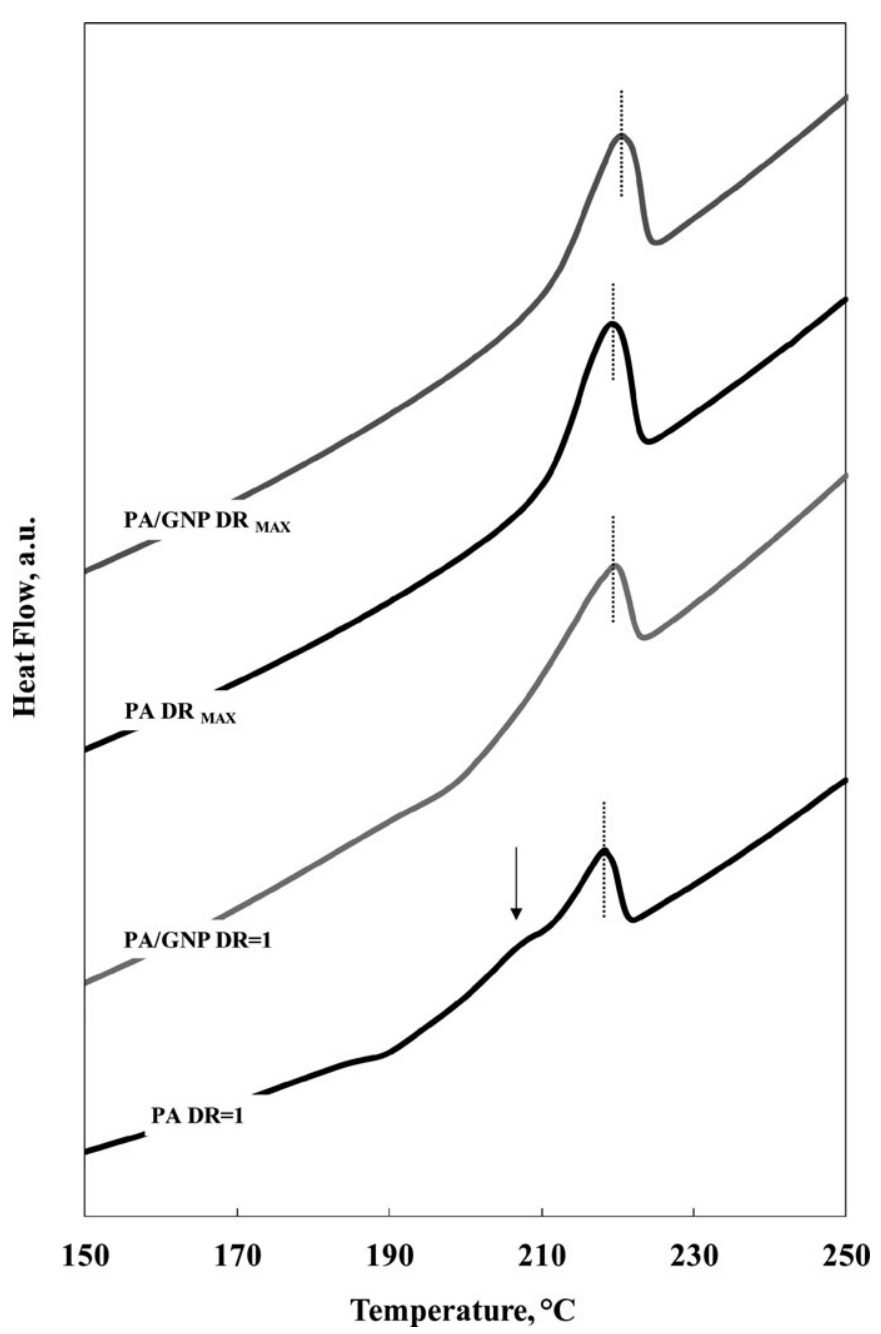

FIGURE 12. DSC traces of the first heating of neat PA and PA/GNP fibers at $D R=1$ and $D R_{M A X}$.

TABLE II

Values of $T_{1 \mathrm{\rho H}}$ for Neat PA and PA/GNP Nanocomposites Fibers at Minimum and Maximum Draw Ratio

\begin{tabular}{lcccccc}
\hline \multicolumn{9}{c}{$T_{1 \rho} H(\mathrm{~ms})$} \\
\hline & & \multicolumn{2}{c}{$\mathrm{PA}$} & & \multicolumn{2}{c}{$\mathrm{PA} / \mathrm{GNP}$} \\
\cline { 3 - 4 } \cline { 7 - 7 } Signal & $\mathrm{ppm}$ & $\mathrm{DR}=1$ & $\mathrm{DR}_{\mathrm{MAX}}$ & & $\mathrm{DR}=1$ & $\mathrm{DR}_{\mathrm{MAX}}$ \\
\hline $\mathrm{C}_{1}$ & 173.0 & 5.1 & 4.7 & & 3.5 & 3.9 \\
$\mathrm{C}_{2}$ & 42.9 & 8.1 & 7.9 & & 4.3 & 5.3 \\
$\mathrm{C}_{3}$ & 40.0 & 5.0 & 5.7 & & 3.4 & 4.8 \\
$\mathrm{C}_{4}$ & 36.6 & 4.7 & 6.6 & & 4.6 & 3.7 \\
$\mathrm{C}_{5}$ & 30.0 & 5.4 & 4.9 & & 5.5 & 4.0 \\
$\mathrm{C}_{6}$ & 26.4 & 5.1 & 5.4 & & 4.3 & 4.3 \\
\hline
\end{tabular}

TABLE III

Values of $T_{1 \mathrm{pc}}$ for Neat PA and PA/GNP Nanocomposites Fibers at Minimum and Maximum Draw Ratio

\begin{tabular}{|c|c|c|c|c|c|}
\hline \multicolumn{6}{|c|}{$T_{1 \rho} C(\mathrm{~ms})$} \\
\hline \multirow[b]{2}{*}{ Signal } & \multirow[b]{2}{*}{$\mathrm{ppm}$} & \multicolumn{2}{|c|}{ PA } & \multicolumn{2}{|c|}{ PA/GNP } \\
\hline & & $D R=1$ & $\mathrm{DR}_{\text {MAX }}$ & $\mathrm{DR}=1$ & $\mathrm{DR}_{\mathrm{MAX}}$ \\
\hline $\mathrm{C}_{1}$ & 173.0 & 35.5 & 28.6 & 21.5 & 15.6 \\
\hline $\mathrm{C}_{2}$ & 42.9 & 11.8 & 11.4 & 9.3 & 6.0 \\
\hline $\mathrm{C}_{3}$ & 40.0 & 8.2 & 10.9 & 10.5 & 5.3 \\
\hline $\mathrm{C}_{4}$ & 36.6 & 9.6 & 7.8 & 9.4 & 7.1 \\
\hline $\mathrm{C}_{5}$ & 30.0 & 10.3 & 8.0 & 11.5 & 11.6 \\
\hline $\mathrm{C}_{6}$ & 26.4 & 8.9 & 7.0 & 4.6 & 5.3 \\
\hline
\end{tabular}

addition. Indeed, in PA/GNP nanocomposite, the shoulder at $210^{\circ} \mathrm{C}$ is not detected even at minimum DR.

In Tables II and III, the values of $T_{1 \rho \mathrm{H}}$ and $T_{1 \rho \mathrm{\rho C}}$, i.e., the spin-lattice relaxation times in rotating frame, for neat PA and nanocomposite fibers at minimum and maximum DR were reported, respectively. The values of $T_{1 \rho \mathrm{H}}$ for neat PA at $\mathrm{DR}=1$ are somewhat homogeneous, and such uniformity persists even after stretching, suggesting a dynamic uniformity. Similar conclusions can be drawn from the analysis of $T_{1 \rho \mathrm{H}}$ values of PA/GNP nanocomposite, indicating a structural uniformity also in this case. Furthermore, the values of $T_{1 \rho \mathrm{C}}$ for unfilled PA and GNP-containing sample slightly decreases, and as expected, this trend is well-pronounced for the signal C1, e.g., carbonyl carbons (see Table III), suggesting reduced interactions between the PA macromolecules upon extensional flow. The addition of GNP nanoparticles, weakening the interactions between the carbonyl carbons of matrix macromolecules, results in the disturbance of the PA dynamics at nano-scale level.

\section{Conclusions}

Microwave- and thermal-treated GNP have been fully characterized, through non-conventional techniques as EELS and SAED, in terms of overall dimensions and number of graphitic layers after expansion. Microwave-treated GNP, with well-exfoliated structure and dimensions comparable to those of native GIC, have been incorporated in PA and the formulated nanocomposite has been subjected to extensional flow, aiming to obtain high performance nanocomposite fibers. Morphological and rheological analyses of PA/GNP nanocomposite allow to infer that GNP are welldispersed into the host matrix, probably forming a semi-3D super-structure throughout the nanocomposite. Upon extensional flow, GNP are able to further exfoliate and to align along the fiber direction, leading to obtain advanced nanocomposite with excellent mechanical performance. Overall, microwave treatment can be considered as an effective method to produce well-exfoliated grafitic structures, suitable for the formulation of functional polymerbased nanocomposites. 


\section{Acknowledgments}

TEM (including EDS and SAED analysis) and NMR experimental data were provided by Centro Grandi Apparecchiature - UniNetLab, University of Palermo, funded by P.O.R. Sicilia 2000-2006, misura 3.15 Azione C Quota Regionale.

\section{References}

1. Xu, J. Z.; Zhong, G. J.; Hsiao, B. S.; Fu, Q.; Li, Z. M. Prog Polym Sci 2013, $39,555$.

2. Pichler, T. Nat Mater 2007, 6, 332.

3. Kim, H.; Abdala, A. A.; Macosko, C. W. Macromolecules 2010, 43, 6515.

4. Allen, M. J.; Tung, V. C.; Kaner, R. B. Chem Rev 2010, 110, 132.

5. Zhang, X.; Rajaraman, B. R. S.; Liu, H.; Ramakrishna, S. RSC Adv 2014, 4, 28987.

6. Novoselov, K. S.; Geim, A. K.; Morozov, S. V.; Jiang, D.; Zhang, Y.; Dubonos, S. V.; Grigorieva, I. V.; Firsov, A. A. Science 2004, 306, 666.

7. Choucair, M.; Thordarson, P.; Stride, J. A. Nat Nanotechnol 2009, 4, 30.

8. Hassan, M. A.; Abdelsayed, V.; Khder, S. R.; Abouzeid, K. M.; Terner, J.; Samy El-Shall, M.; Al-Resayes, S. I.; El-Azhary, A. A. J Mater Chem 2009. $19,3832$.

9. Cai, M.; Thorpe, D.; Adamson, D. H.; Schniepp, H. C. J Mater Chem 2012, $22,24992-25002$

10. Schniepp, H. C.; Li, J. L.; McAllister, M. J.; Sai, H.; Herrera-Alonso, M.; Adamson, D. H.; Prud'homme, R. K.; Car, R.; Saville, D. A.; Aksay, I. A. J Phys Chem B 2006. 110, 8535.

11. Hu, K.; Kulkarni, D. D.; Choi, I.; Tsukruk, V. V. Prog Polym Sci 1934, 2014, 39.

12. Zhou, X. F.; Liu, Z. P. Chem Commun 2010, 46, 2611.

13. Gu, W.; Zhang, W.; Li, X.; Zhu, H.; Wie, J.; Li, Z.; Shu, Q.; Wang, C.; Wang, K.; Shen, W. J Mater Chem 2009, 19, 3367.

14. Khan, U.; O’Neill, A.; Lotya, M.; De, S.; Coleman, J. N. Small 2010, 6, 864.

15. Boukhvalov, D. W.; Katsnelson, M. I. Nano Lett 2008, 8, 4373.
16. Dreyer, D. R.; Park, S.; Bielawski, C. W.; Ruoff, R. S. Chem Soc Rev 2010, $39,228$.

17. Vadahanambi, S.; Jung, J. H.; Oh, I. K. Carbon 2011, 49, 4449.

18. Kumar, R.; Kim, H. J.; Park, S.; Srivastava, A.; Oh, I. K. Carbon 2014, 79, 192.

19. Liu, L.; Shen, Z.; Liang, S.; Yi, M.; Zhang, X.; Ma, S. J Mater Sci 2014, 49, 321.

20. Gadgil, B.; Damlin, P.; Heinonen, M.; Kvarnström, C. Carbon 2015, 89, 53.

21. Yu, C.; Li, D.; Wu, W.; Luo, C.; Zhang, Y.; Pan, C. J Mater Sci 2014, 24, 8311.

22. Dintcheva, N. T.; Arrigo, R.; Morreale, M.; La Mantia, F. P.; Matassa, R.; Caponetti, E. Polym Adv Techn 2011, 22, 1612.

23. Dintcheva, N. T.; Arrigo, R.; Nasillo, G.; Caponetti, E.; La Mantia, F. P. Macromol Mat Eng 2011, 296, 645.

24. Dintcheva, N. T.; Arrigo, R.; Nasillo, G.; Caponetti, E.; La Mantia, F. P. J App Polym Sci 2013, 129, 2479.

25. Arrigo, R.; Dintcheva, N. T.; Nasillo, G.; Caponetti, E. Polym Comp 1020, $2015,36$.

26. Iswandi, I.; Sahari, J.; Sulong, A. B. Key Eng Mater 2011, 471, 109.

27. Petrach, E.; Abu-Isa, I.; Wang, X. J Compos Mater 2010, 44, 1665.

28. Zhou, Y.; Bao, Q.; Tang, L. A. L.; Zhong, Y.; Loh, K. P. Chem Mater 2009, $21,2950$.

29. Zheng, J.; Liu, H. T.; Wu, B.; Di, C. A.; Guo, Y. L.; Wu, T.; Yu, G.; Liu, Y. Q.; Zhu, D. B. Sci Rep 2012, 2, 662.

30. Hartmann, S. R.; Hahn, E. L. Phys Rev 1062, 128, 2042.

31. Stadelmann, P. JEMS - EMS java version, 2004

32. Malis, T.; Cheng, S. C.; Egerton, R. F. J Electron Microsc Tech 1988, 8, 193.

33. Pötschke, P.; Fornes, T. D.; Paul, D. R. Polymer 2002, 43, 3247.

34. Liu, C.; Zhang, J.; He, J.; Hu, G. Polymer 2003, 44, 7529.

35. Wu, H.; Lu, C.; Zhang, W.; Zhang, X. Mater Design 2013, 52, 621.

36. La Mantia, F. P.; Arrigo, R.; Morreale, M. Europ Polym J 2014, 54, 11.

37. Schreiber, R.; Veeman, W. S.; Gabrielse, W.; Arnauts, J. Macromolecules 1999, 32, 4647.

38. Murthy, N. S.; Bray, R. G.; Correale, S. T.; Moore, R. A. F. Polymer 1995, 36, 3863. 